\title{
The Effect of Production Parameters on the Foaming Behavior of Spherical-shaped Aluminum Foam
}

\author{
Arif Uzun ${ }^{a *}$, Mehmet Turker ${ }^{b}$ \\ ${ }^{a}$ Department of Welding Technology, Cide Rufat Ilgaz Vocational School, 37600, \\ Kastamonu University, Cide, Kastamonu, Turkey \\ ${ }^{b}$ Department of Metallurgy, Faculty of Technology, Gazi University, Ankara, Turkey
}

Received: February 6, 2013; Revised: October 30, 2013

\begin{abstract}
The effect of production parameters on the foaming behavior of spherical-shaped aluminum foam was studied. Elemental powders of Alumix 231 and $1 \% \mathrm{TiH}_{2}$ were mixed, compacted at $600 \mathrm{MPa}$ pressure by using a uniaxial action press to produce blanks with $50 \times 30 \times 10 \mathrm{~mm}$ in dimensions. These blanks were pre-heated at $550{ }^{\circ} \mathrm{C}$ in a furnace for $180 \mathrm{~min}$ and then deformed by $10,30,50$ and $70 \%$ by using an eccentric press. They were cut into square shape and foamed at temperatures between $650{ }^{\circ} \mathrm{C}$ and $710^{\circ} \mathrm{C}$. It was experimentally found that, the volume expansion rate of foam increases but the maximum foaming duration decreases with increasing the deformation rate and foaming temperature. In these studies $70 \%$ deformation and 3.5 minutes foaming duration were found to be the best for the production of spherical foams. This was determined by obtaining the maximum expansion, lower density and homogeneously distributed pores with spherical foams. It was also found that $10 \%$ deformation rate was not enough for foaming.
\end{abstract}

Keywords: APM foam, Al foam, powder metallurgy, porosity

\section{Introduction}

Metallic foams have extremely superior mechanical, physical and acoustic properties. They are a group of new materials whose production methods are rapidly developing ${ }^{1}$. Combination of these properties provides that these structures to be widely used in structural and functional applications. Al-based foams have a great potential to be utilized in the fields of automobile, aerospace, shipment, railway and civil construction ${ }^{1-4}$. Metallic foams have been produced using different manufacturing methods because of intensive research in this field and the developments in today's technology. Currently, the most commonly used production methods are the gas injection into mold, the addition of foaming agents and powder metallurgy $y^{5-7}$. In powder metallurgy method, aluminum foams are made by expansion of foamable precursor in foaming moulds. The mould is heated in a furnace until the expansion process of precursor. The foaming agent in structure during the foaming process decomposes and releases gas which expands the liquid metal. In this method for aluminum and its alloys as a foaming agent is used usually $\mathrm{TiH}_{2}$ or $\mathrm{ZrH}_{2}$. However, $\mathrm{CaCO}_{3}$ and dolomite powders can be used effectively instead of $\mathrm{TiH}_{2}$ as foaming agent. But the cell morphology varies with the foaming temperature ${ }^{8,9}$. Homogeneous heat transfer into the precursor, foaming mould design and precursor geometry are most important for high quality near-net shape aluminum foam part production in moulds. If these parameters cannot be controlled non-uniform expansion can occurs ${ }^{10,11}$. But the spherical- shaped metallic foam parts are produced without a mould. They are produced by

*e-mail: auzun@kastamonu.edu.tr foaming a precursor material with APM (Advanced Pore Morphology) technology which is developed by IFAM in Germany $^{12}$. This technology consists of two main steps as the foam expansion and the foam shaping. The precursor materials are cut into small volumes that are foamed without molds in a continuous belt furnace in production ${ }^{6,13}$. Surface tension of the metal melt shapes the elements spherical. Due to gravity force the geometry is not perfectly spherical ${ }^{10,11}$. The result is a high reproducibility of the expansion level in contrast to foam expansion in moulds. The manufactured parts have a relatively small volume (volume $<1 \mathrm{~cm}^{3}$ ). These parts are combined with a simple bonding technique (Figure 1). Therefore, APM foam parts manufacturers provide maximum flexibility for their users ${ }^{12}$. They can be used as team members in front of vehicles by filling inside of steel pipes ${ }^{13-15}$. Recently, the researchers has focused on the mechanical properties of the single or hybrid APM foams ${ }^{16,17}$. However, the researches on the effect of process parameters in production of these materials are still very limited. The aim of this study was to optimize sphericalshaped aluminum foam production parameters.

\section{Materials and Experimental Process}

In this study, $1 \mathrm{wt} \% \mathrm{TiH}_{2}$ powders (purity: $98 \%$, particle size: $<45 \mu \mathrm{m}$ ) supplied from Aldrich were added to Alumix 231 powder (purity: 99\%, particle size: $<200 \mu \mathrm{m}$ ) supplied from Eckart and were mixed in a three dimensional turbola for $30 \mathrm{~min}$. Mixed powders were then compacted under $600 \mathrm{MPa}$ single action pressure to produce blanks with $50 \times 30 \times 10 \mathrm{~mm}$ in dimensions ${ }^{18}$. These blanks were 
pre-heated at $550{ }^{\circ} \mathrm{C}$ in a furnace for 180 minutes due to the mismatch between the decomposition temperature of foaming agent (at about $\left.400-600{ }^{\circ} \mathrm{C}\right)^{[19,20]}$ and then deformed by $10,30,50$ and $70 \%$ by using an eccentric press. They were cut into shapes of square and foamed at various temperatures $\left(650,670,690,710{ }^{\circ} \mathrm{C}\right)$ from 2 to 5 minutes with the interval of 30 seconds and cooled to room temperature. Figure 2 shows the production stages of spherical-shaped aluminum foam. At least three and more samples for each configuration were investigated in experiments.

The density of the produced foam parts $\left(\rho_{s}\right)$ is determined by Archimede's method. The volume expansion was then calculated by using Equation 1:

$$
\text { Expansion }=\frac{\left(v^{*}-v\right)}{v} \times 100 \%
$$

Where; $v^{*}$ and $v$ are the specimen volume after and before foaming. The porosities of $\mathrm{Al}$ foam were calculated using the following Equation 2:

$$
\text { Porosity }=\frac{\left(\rho-\rho^{*}\right)}{\rho} \times 100 \%
$$

Where; $\rho^{*}$ and $\rho_{\mathrm{s}}$ are the densities of $\mathrm{Al}$ foams and the cell wall material respectively.

\section{Results and Discussion}

\subsection{Volume expansion}

Figure 3 shows the effect of foaming temperature on the volume expansion rate of precursor samples deformed by $10 \%$. As seen in the graph, samples did not show any detectable volume expansion (under $40 \%$ ) at any time. For example, the maximum expansion of $37 \%$ after $3.5 \mathrm{~min}$ at $690{ }^{\circ} \mathrm{C}$ was obtained in the precursor samples that were

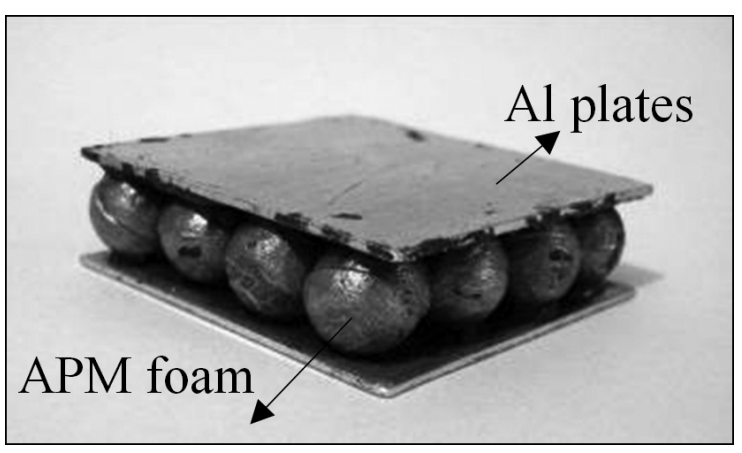

Figure 1. Sandwich structure with cellular core layer. deformed by $10 \%$. On the other hand, the foamed sample for 4 min at $650{ }^{\circ} \mathrm{C}$ exhibited maximum volume expansion rate of $29 \%$. The results indicated that the foaming temperature was not effective for $10 \%$ deformed samples. This was attributed to the inadequate deformation rate which was not enough for retaining the entrapped gas during the foaming period.

Figure 4 shows the effect of foaming temperature on the volume expansion rate of samples deformed by $30 \%$. As seen in the graph, the precursor samples foamed at $650{ }^{\circ} \mathrm{C}$ and $670{ }^{\circ} \mathrm{C}$ temperatures reached the maximum expansions in $4 \mathrm{~min}$. During this period the volume expansion rates of $242 \%$ and $252 \%$ were obtained respectively. Moreover, the samples foamed at $690{ }^{\circ} \mathrm{C}$ and $710{ }^{\circ} \mathrm{C}$ exhibited expansion rates of $255 \%$ at $3.5 \mathrm{~min}$ and $204 \%$ at $3 \mathrm{~min}$ respectively. The volume expansion rates of samples were found to decrease after these periods were exceeded. The samples deformed by $50 \%$ and $30 \%$ exhibited similar foaming behavior as shown in Figure 5. However, the volume expansion rate of $50 \%$ deformed sample was higher than the sample deformed by $30 \%$.

Figure 6 shows the maximum volume expansion rates of $70 \%$ deformed samples at different foaming temperatures. As seen in the graph, the samples foamed for 4 minutes at $650{ }^{\circ} \mathrm{C}$ exhibited maximum volume expansion rate of $449 \%$. On the other hand, the foamed samples at $670{ }^{\circ} \mathrm{C}, 690^{\circ} \mathrm{C}$ and $710{ }^{\circ} \mathrm{C}$ exhibited maximum volume expansion rates of $523 \%, 556 \%$ and $338 \%$ at $4,3.5$ and 3 min foaming durations respectively. According to the aforementioned results it can be said that high temperature reduced the foaming duration. This situation is based on the fact that hydrogen pressure (from the dissolution of $\mathrm{TiH}_{2}$ ) is increased with increasing temperature. Thus, the acceleration in the releasing of hydrogen causes rapid coalescence of bubbles ${ }^{21}$. However, the volume expansion rates started to decrease again when these periods are exceeded the normal foaming duration and no more hydrogen gas is released and the foam begins to decay which leads to collapsing ${ }^{22}$.

Figure 7 shows the samples foamed for $3.5 \mathrm{~min}$ after being deformed at various rates. Spherical-shaped aluminum foam samples were obtained by means of free-form foaming in our previous studies. Because of the surface tension during foaming process, the precursor samples were put into spherical shape ${ }^{12}$. However, the samples could not get exactly a spherical shape due to the mass of the melted samples. As seen in Figure 7, the $70 \%$ deformed sample has the most spherical in shape. As mentioned previously, the blowing agent fails to be held in the structure properly with decreasing of deformation rate. The white dashed lines on the image indicate the cross section of samples before the foaming so that the foaming ratio can be understood easily.

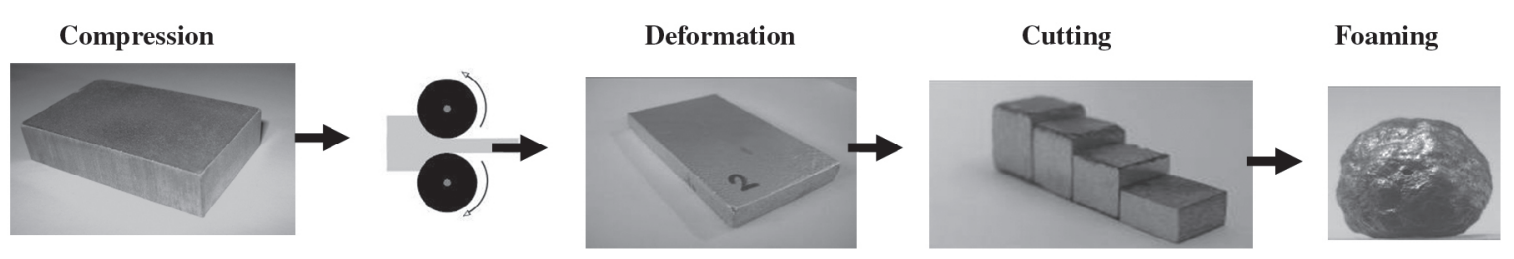

Figure 2. Production stages of spherical-shaped aluminum foam. 


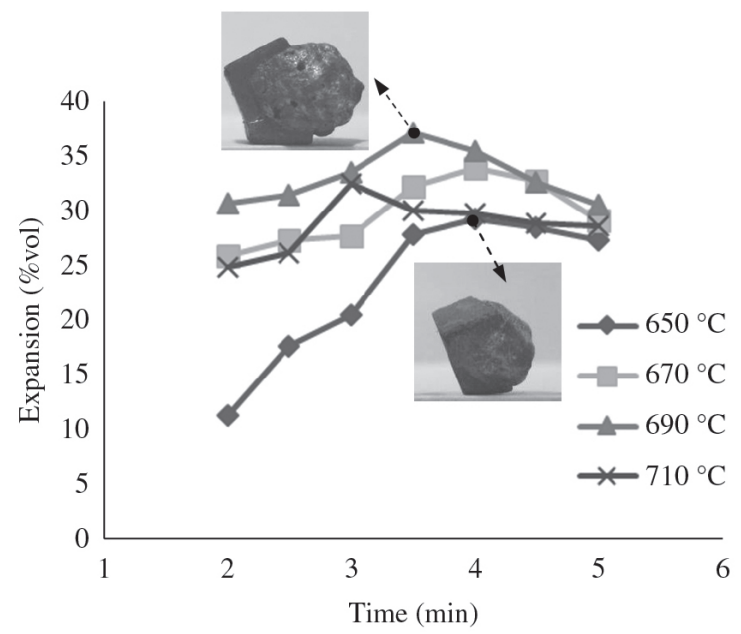

Figure 3. Expansion rates of $10 \%$ deformed samples at various foaming temperatures.

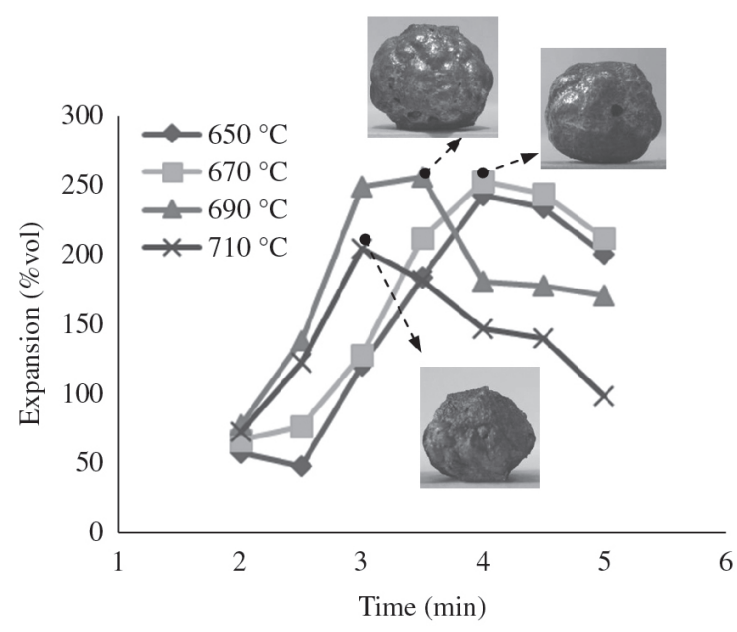

Figure 4. Expansion rates of $30 \%$ deformed samples at various foaming temperatures.

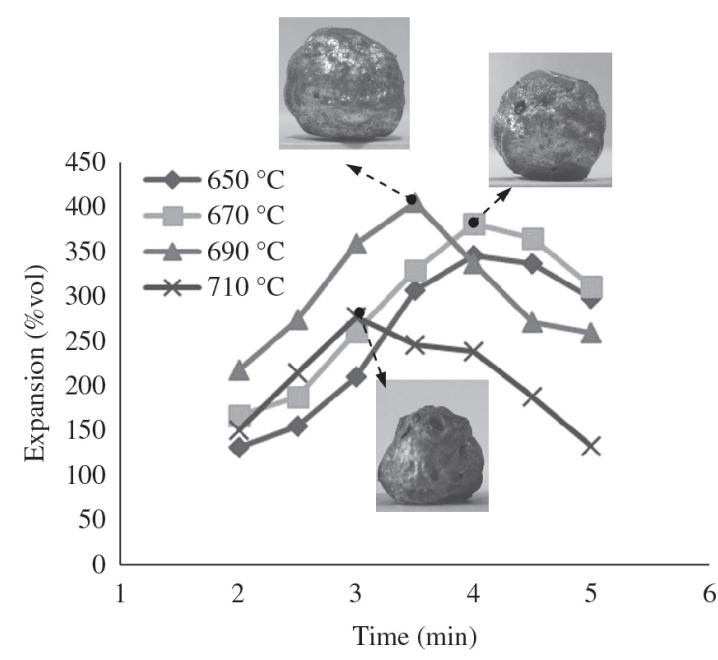

Figure 5. Expansion rates of $50 \%$ deformed samples at various foaming temperatures.

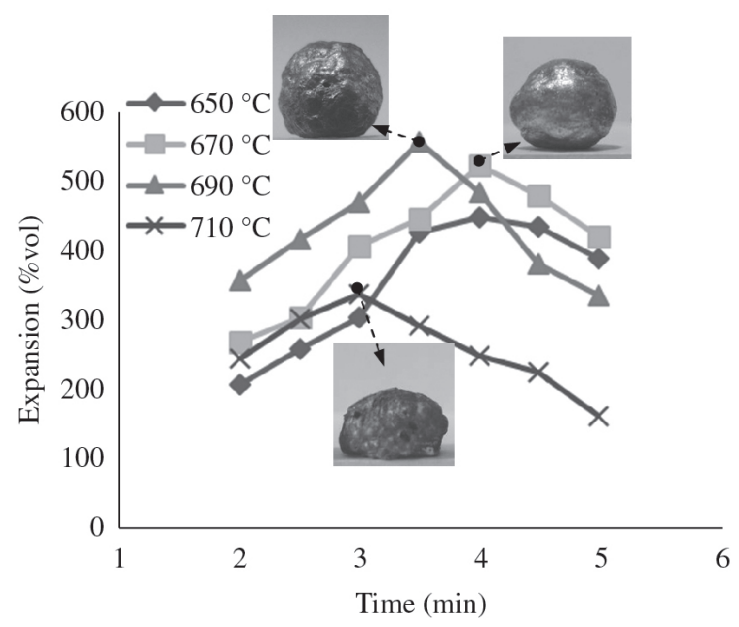

Figure 6. Expansion rates of $70 \%$ deformed samples at various foaming temperatures.
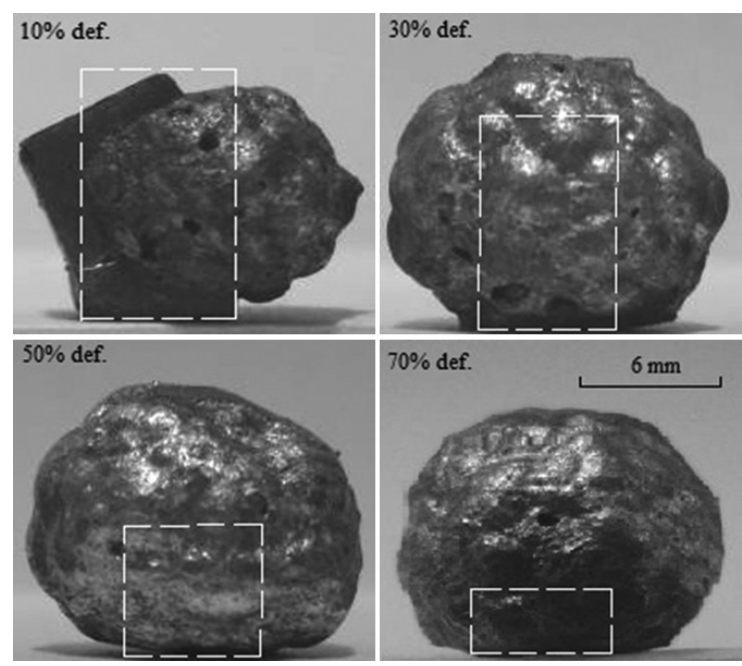

Figure 7. The appearance of the samples foamed for $3.5 \mathrm{~min}$ after being deformed at various rates.

The density of samples increased with increasing the rate of deformation which is also indicated in the literature ${ }^{23}$. Thus, the blowing agent cannot escape from the structure during the foaming process. The densities of precursor samples depend on the amount of deformation rates given in Table 1.

\subsection{Density, porosity and structure of pores}

In this section, the densities of samples that exhibited maximum volume expansion at $690^{\circ} \mathrm{C}$ were compared and the graph was obtained (Figure 8). As seen in the graph, the lowest density and the maximum expansion rate were reached after foaming for $3.5 \mathrm{~min}$. In the same period of exposure the densities of samples deformed by $70 \%, 50 \%$, $30 \%$ and $10 \%$ were calculated to be $0.40,0.52,0.75$ and $1.99 \mathrm{~g} / \mathrm{cm}^{3}$ respectively. But the densities of samples increased after that time up to 5 minutes. Some samples that deformed by $70 \%$ exhibited some cracks. The deformation 
Table 1. The densities of precursor samples depending upon the amount of deformation rates.

\begin{tabular}{lcccc}
\hline Deformation Rate $(\%)$ & 10 & 30 & 50 & 70 \\
Average Density $\left(\mathrm{g} / \mathrm{cm}^{3}\right)$ & 2.42 & 2.48 & 2.53 & 2.68 \\
\hline
\end{tabular}

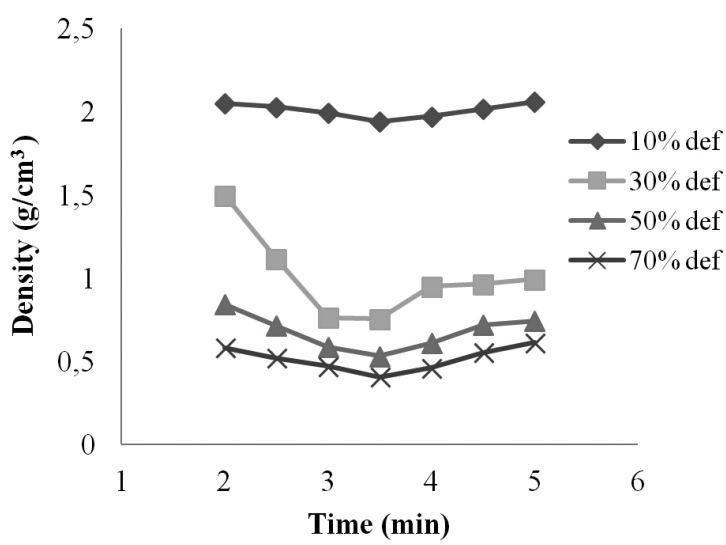

Figure 8. Density of samples foamed at $690{ }^{\circ} \mathrm{C}$.

process was controlled with structural defects, which was believed to have resulted in some cracks.

The increase in the density is due to the escaping of the trapped gas from the pores particularly on the highly deformed samples. This process also results in the collapsing of the foamed materials due to the escaping of entrapped gas from the molten metal easily. In addition, significant differences in the pore structure of samples were formed. Figure 9 shows the structure of pores of foam samples exhibited the maximum volume expansion at $690{ }^{\circ} \mathrm{C}$. When we increased the foaming duration to $3.5 \mathrm{~min}$, small amount of porosity (27\%) was seen on the sample deformed by $10 \%$ as shown in Figure 9 . However, $50 \%$ deformed sample exhibited more pores $(80 \%)$ which were smaller than those seen in the sample deformed by $70 \%$ which exhibited homogeneously distributed spherical porosity (84\%).

\section{Conclusions}

The foaming behavior of spherical-shaped aluminum foam depending on the production parameters was

\section{References}

1. Ashby MF, Evans A, Fleck NA, Gibson LJ, Hutchinson JW and Wadley HNG. Metal foams: a design guide. Oxford: Butterworth, Heinmann; 2000.

2. Banhart J. Manufacture, characterization and application of cellular metals and metal foams. Progress in Materials Science. 2001; 46:559-632. http://dx.doi.org/10.1016/S00796425(00)00002-5

3. Degischer HP and Kriszt B. Handbook of Cellular Metals. Weinheim: Wiley-VCH; 2002. http://dx.doi. org/10.1002/3527600558

4. Lefebvre LP, Banhart J and Dunand DC Porous metals and metallic foams: Current status and recent developments. Advanced Engineering Materials. 2008;10:775-787. http:// dx.doi.org/10.1002/adem.200800241

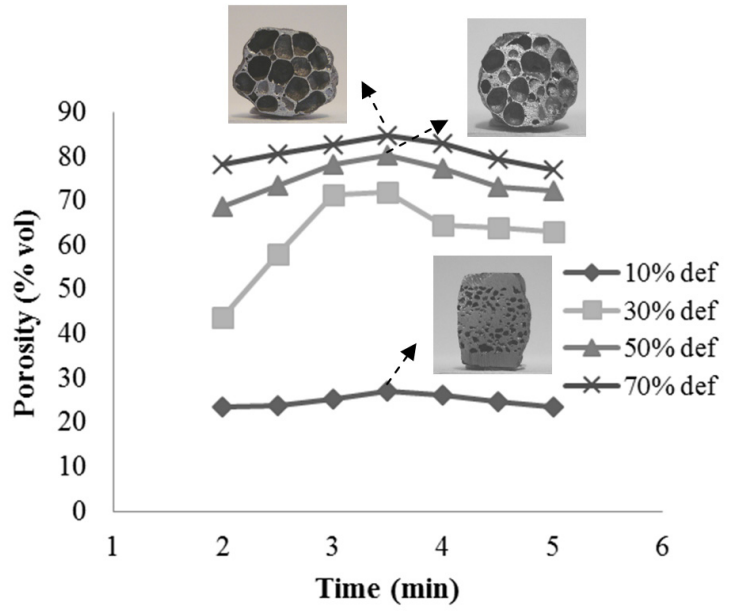

Figure 9. The structure of samples foamed $690^{\circ} \mathrm{C}$.

investigated. It was experimentally found that, the volume expansion rate of foam increases but the maximum foaming duration decreases with increasing the deformation rate and foaming temperature. In these studies $70 \%$ deformation and 3.5 minutes foaming duration were found to be the best for the production of spherical foams. This was determined by obtaining the maximum volume expansion, lower density and homogeneously distributed pores with spherical foams. It was also found that $10 \%$ deformation rate was not enough for foaming, $50 \%$ deformation on the other hand, showed some pores after $3.5 \mathrm{~min}$ foaming, but they were not homogeneously distributed although the foamed sample was almost spherical in shape. It was found that the foaming duration shortened with increasing foaming temperature.

\section{Acknowledgements}

Financial support for this study was granted by The Scientific and Technological Research Council of Turkey (TUBITAK) with project number 106M513.

5. Baumaster J. Methods for manufacturing foamable metal bodies. US patent, 1992.

6. Li DW, Li J, Li T, Sun T, Zhang X and Yao GC. Preparation and characterization of aluminum foams with $\mathrm{ZrH}_{2}$ as foaming agent. Transactions of Nonferrous Metals Society of China. 2011; 21:346-352. http://dx.doi.org/10.1016/S10036326(11)60720-6

7. Raj RE and Daniel BSS. Aluminum melt foam processing for light-weight structures. Materials and Manufac. Processes. 2007; 22:525-530. http://dx.doi. org/10.1080/10426910701236072

8. Mondal DP, Jha N, Gull B, Das S and Badkul A. Microarchitecture and compressive deformation behaviour of Al-alloy (LM13)-cenosphere hybrid Al-foam prepared using $\mathrm{CaCO}_{3}$ as foaming agent. Materials Science \& 
Engineering A. 2013;560:601-610. http://dx.doi.org/10.1016/j. msea.2012.10.003

9. Kevorkijan V, Skapin SD, Paulin I, Sustarsic B, Jenko M and Lazeta M Influence of the foaming precursor's composition and density on the foaming efficiency, microstructure development and mechanical properties of aluminum foams. Materiali in tehnologije/Materials and Technology 2011;45:95-103.

10. Stöbener K. Advanced pore morphology (APM). Aluminiumschaum [dissertation]. University of Bremen; 2007.

11. Stöbener K and Rausch G. Aluminium foam-polymer composites: processing and characteristics. Journal of Materials Science. 2009; 44:1506-1511. http://dx.doi. org/10.1007/s10853-008-2786-8

12. Stöbener K, Baumeister J, Rausch G and Rausch M. Forming metal foams by simpler methods for cheaper solutions. Metal Powder Report. 2005; 60:12-16. http://dx.doi.org/10.1016/ S0026-0657(05)00316-4

13. Stöbener K, Lehmhus D, Avalle M, Peroni L and Busse M. Aluminum foam-polymer hybridstructures (APM aluminum foam) in compression testing. International Journal of Solids and Structures. 2008; 45:5627-5641. http://dx.doi. org/10.1016/j.ijsolstr.2008.06.007

14. Weise J, Ruparelia DH, Wichmann M and Baumeister J. Investigation of the mechanical behavior of particulate aluminum-epoxy hybrid foams in dependence upon the metal and polymer content. In: Proceedings of the CELLMAT; 2010; Dresden. Dresden; 2010.

15. Rausch G, Stobener K and Bassan D. Improving structural crashworthiness using metallic and organic foams. In: Proceedings of the International Symposium Cellular Metals for Structural and Functional Applications; 2005; Dresden. Stuttgart: Fraunhofer IRB Verlag; 2005.
16. Baumeister J, Monno M, Goletti M, Mussi V and Weise J. Dynamic behavior of hybrid APM (Advanced Pore Morphology foam) and aluminum foam filled structures. Metals. 2012; 2:211-218. http://dx.doi.org/10.3390/ met2020211

17. Vesenjak M and Krstulovic-Opara L. Experimental testing of single APM spheres. In: Proceedings of the 14th International Conference on Experimental Mechanics; 2010; Poitiers. EPJ Web of Conferences; 2010. v. 6, p. 1-7. http://dx.doi. org/10.1051/epjconf/20100602005

18. Rudianto H, Yang S, Nam K and Kim Y. Mechanical properties of $\mathrm{Al}-14 \mathrm{Si}-2.5 \mathrm{Cu}-0.5 \mathrm{Mg}$ aluminum-silicon P/M alloy. Reviews on Advanced Materials Science. 2011; 28:145-149

19. Bhosle V, Baburaj EG, Miranova M and Salama K. Dehydrogenation of $\mathrm{TiH}_{2}$. Materials and Engineering A. 2003; 356:190-199. http://dx.doi.org/10.1016/S09215093(03)00117-5

20. Zeppelina F, Hirschera M, Stanzickb H and Banhart J. Desorption of hydrogen from blowing agents used for foaming metals. Composites Science and Technology. 2003; 63:22932300. http://dx.doi.org/10.1016/S0266-3538(03)00262-8

21. Yang CC and Nakae H. Foaming characteristics control during production of aluminum alloy foam. Journal of Alloys and Compounds. 2000; 313:188-191. http://dx.doi.org/10.1016/ S0925-8388(00)01136-1

22. Duarte I and Banhart J. A study of aluminum foam formation kinetics and microstructure. Acta Materialia. 2000; 48:23492362. http://dx.doi.org/10.1016/S1359-6454(00)00020-3

23. German RM. Powder Metallurgy and Particulate Materials. Metal Powder Industries Federation; 2005. 